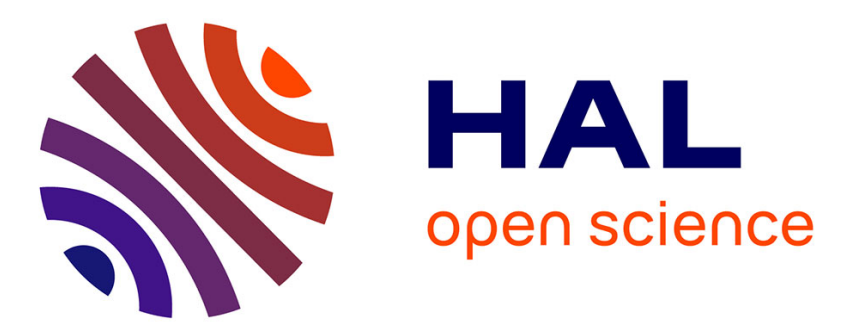

\title{
Growth and neurodevelopment outcome in symmetric versus asymmetric small for gestational age term infants
}

\author{
Emilie Maciejewski, I Hamon, J Fresson, J-M Hascoet
}

\section{To cite this version:}

Emilie Maciejewski, I Hamon, J Fresson, J-M Hascoet. Growth and neurodevelopment outcome in symmetric versus asymmetric small for gestational age term infants. Journal of Perinatology, 2016, 36 (8), pp.670-675. 10.1038/jp.2016.48 . hal-02957005

\section{HAL Id: hal-02957005 \\ https://hal.science/hal-02957005}

Submitted on 4 Oct 2020

HAL is a multi-disciplinary open access archive for the deposit and dissemination of scientific research documents, whether they are published or not. The documents may come from teaching and research institutions in France or abroad, or from public or private research centers.
L'archive ouverte pluridisciplinaire HAL, est destinée au dépôt et à la diffusion de documents scientifiques de niveau recherche, publiés ou non, émanant des établissements d'enseignement et de recherche français ou étrangers, des laboratoires publics ou privés. 
Growth and neurodevelopment outcome in symmetric versus asymmetric small for gestational age term infants

\section{Authors}

MACIEJEWSKI Emilie ${ }^{1}$, MD

HAMON Isabelle ${ }^{1,3}, \mathrm{MD}, \mathrm{PhD}$

FRESSON Jeanne ${ }^{2}$, MD

HASCOET Jean-Michel ${ }^{1,3}$, MD

1 Department of Neonatology, Maternité Régionale, CHRU Nancy, 10 rue du Dr Heydenreich, 54035 Nancy, France

${ }^{2}$ Department of Medical Information, CHRU Nancy, 10 rue du Dr Heydenreich, 54035 Nancy, France

${ }^{3}$ Universite de Lorraine, EA 3450 DevAH, Faculté de Médecine de Nancy, 9 avenue de la forêt de Haye, 54500 Vandoeuvre-les-Nancy, France

Running Title: Small for Gestational Age Term infants' outcome

\section{Corresponding author}

MACIEJEWSKI Emilie, Department of Neonatology, Maternité Régionale, CHRU Nancy, 10 rue du Dr Heydenreich, 54035 Nancy, France.

Tel : +33 3833436 45. Fax : +33383344411

emilie.maciejewski@neuf.fr 


\section{Abstract}

Objective: few studies compared growth and neurodevelopment outcome between asymetric (aSYM) and symmetric (SYM) Small for Gestational Age (SGA) term infants. We aimed at evaluating their respective outcome at 9 months postnatal age.

Study Design: cohort study including infants born in 2010-2011 with a birth weight $<5^{\text {th }}$ centile and a head circumference (HC) below (SYM) or above (aSYM) the $5^{\text {th }}$ centile. Catch-up growth was defined as weight, height and $\mathrm{HC} \geq-2 \mathrm{SD}$ of WHO reference values. Neurodevelopment was evaluated with Brunet-Lezine test items.

Result: 194/6586 infants were SGA: $38.7 \%$ SYM and 61.3\% aSYM. The aSYM group showed better catch-up growth (85 vs. $70 \%, \mathrm{p}=0.03)$ with larger $\mathrm{HC}(44.9 \pm 1.6$ vs. $43.7 \pm 1.2 \mathrm{~cm}, \mathrm{p}<.0001)$. No difference in neurodevelopmental screening was observed between SGA groups, but infants without any catch-up growth were at higher risk of delayed outcome.

Conclusion: Term SGA infants must be closely followed, regardless of their characteristics, to improve their outcome.

\section{Keywords}

Small for Gestational Age; Foetal Growth Restriction, Catch up growth; Head Circumference; Neurodevelopment. 


\section{Introduction}

Foetal growth restriction (FGR) is a dynamic growth disorder in foetuses. The term "small for gestational age" (SGA) refers to infants with a weight below a statistical limit based on a healthy newborn population at a given time. Some of them have FGR, others are just constitutionally small and behave like appropriate for gestational age infants. To minimize this problem, Lee and others suggested considering "SGA" infants only when birth weight is at least 2 standard deviations (SD) below the mean weight for a given gestational age $(1,2)$. SGA newborns can be classified into two groups: symmetric (SYM) SGA, where body weight and head circumference $(\mathrm{HC})$ are both below the statistical limits for gestational age; and asymmetric (aSYM) SGA, where the HC is "preserved", or above the statistical limit for gestational age. In the antenatal period, the ratio of head/abdominal circumference can also be used to define symmetric or asymmetric characteristic (6). In the neonatal period, there are many other ways to define the proportionality of SGA newborns, as the Ponderal Index (PI) score, calculated as the ratio of birthweight (in grams) $\times 100 /$ the cube of crown-heel birth length (in centimeters). The cephalization index $(\mathrm{HC}$ (in centimeters)/birthweight (in grams) $\times 100)$ can also be used, and seems to be associated with long term neurodevelopment (16). Regardless the definition used, among SGA newborns, about $45 \%$ are SYM and 55\% are aSYM according to recent studies $(3,4)$.

The aetiologies of FGR resulting in SGA newborns are complex and sometimes misjudged. It is classically accepted that SYM FGR occurs early, during the first trimester of pregnancy, due to toxic exposure or foetal aberration (genetic, metabolic, or infectious disorder). In contrast, aSYM FGR is thought to occur later, during the second or third trimester of pregnancy, due to maternal vascular disorders. Studies have suggested that these associations might not be as clearly defined as they are generally thought to be $(5,6)$. 
SGA newborns with FGR are at increased risk of neonatal complications, such as mortality, prematurity, neonatal asphyxia, hypothermia, hypoglycaemia, hypocalcaemia, polycythaemia, and sepsis (7-10).

Previous studies have reported that about $10 \%$ of SGA newborns do not catch up to a normal growth size within the first few years of life. According to recent literature, $80 \%$ of SGA infants would show catch-up growth and reach a normal size at 9 months $(11,12)$. Catch-up growth in the first years of life appears to be a physiological compensatory process that follows a period of foetal growth restriction (13). However, few studies have evaluated whether there might be a difference in catch-up growth between SYM and aSYM SGA infants. Growth seems to be not as good in SYM SGA infants as in aSYM SGA infants (3).

Outcome studies have focused on neurodevelopment in premature SGA newborns, and there are little data on term SGA newborns. Term SGA infants show less adaptation problems than premature SGA newborns as compared to AGA otherwise comparable infants. Therefore, term SGA infants' outcome might be underestimated but data are controversial (3,13-15). Nevertheless, several follow-up studies from 8 months to 18 years have suggested that SGA infants may not achieve the same level of neurodevelopment as that achieved by appropriate for gestational age (AGA) infants $(3,14,15)$. However, few of these studies took into account the SYM or aSYM characteristic. For some authors, neurodevelopment outcome is better when catch-up growth, especially brain growth, achieved a normal size within the first years of life (1620). Thus, some questions remain unresolved about growth and neurological development.

The main purpose of the present study was to determine whether catch-up growth at 9 months postnatal age was different between symmetric or asymmetric SGA infants born 
at term, and according to the aetiology of the FGR. The secondary objective was to compare neurodevelopment in these groups of infants.

\section{Patients and Methods}

This retrospective cohort study included all infants born at the Regional Maternity Hospital of Nancy, France, from January 2010 to December 2011. Inclusion criteria were: $\geq 37$ weeks gestation; birth weight below the $5^{\text {th }}$ percentile of the French reference growth curves adapted to our population (AUDIPOG; corrected for gestational age and sex) (21). Families had to reside in the Department of Meurthe-et-Moselle, where the Maternity ward is located. Exclusion criteria were: stillborn, prematurity, congenital malformations, and multiple pregnancies.

We defined two groups of infants: SYM SGA with HC below the $5^{\text {th }}$ percentile, and aSYM SGA with $\mathrm{HC}$ above the $5^{\text {th }}$ percentile of the reference growth curves.

\section{Data collection}

Data for patients' selection was acquired from the Medical Information Department database in our level III institution, where perinatal data are routinely and prospectively collected. For included patients, data for antenatal and neonatal periods were acquired from the medical records of each child and corresponding birth mother.

Data on growth and neurodevelopmental screening were collected from the 9-month health certificate, which is systematically established by paediatricians during a standardised routine visit scheduled according to the national healthcare follow-up programme in France. We accessed these data from the Maternal and Child Protection database of the Department of Meurthe-et-Moselle.

For the antenatal period, we recorded the mother's age and gravidity. The socioeconomic status was described as: families with social worker support or families with social health insurance. From the obstetric record, we determined whether the FGR 
diagnosis was mentioned in the antenatal period, at what gestational age it was diagnosed, and it's presumed aetiological diagnosis. For all cases, the same investigator retrospectively searched for the available documents for defining the etiologic diagnosis. We then classified the FGR aetiologies into five main categories: placental origin, maternal smoking, maternal addiction, chronic maternal disease, and other/undetermined aetiologies.

In the placental origin category, we included maternal hypertension (defined by a systolic blood pressure $\geq 140 \mathrm{mmHg}$ and/or a diastolic blood pressure $\geq 90 \mathrm{mmHg}$ ); preeclampsia (maternal hypertension and proteinuria $\geq 0.3 \mathrm{~g} / 24 \mathrm{~h}$ ); HELLP syndrome (haemolysis, elevated liver enzymes, and thrombocytopenia); and eclampsia (maternal hypertension and seizures). In the placental origin category, we also included Doppler abnormalities (uterine artery notch after 26 weeks gestational age) and placentas with proven typical histopathological lesions (foci of infarction, ischaemia, or villitis).

In the maternal addiction category, we included maternal drug use (alcohol, illegal substances) and/or drug substitution treatment.

When the tobacco was the only one found aetiology, the diagnosis was classified in the maternal smoking category.

In the maternal chronic disease category, we included diabetes, endocrine disorders, autoimmune diseases, and other chronic maternal diseases that may cause FGR (maternal chronic medication, maternal under-nutrition). Any proven maternal-foetal infections were placed in the other/undetermined category.

For the neonatal period, we recorded the following data: gestational age, antenatal corticosteroid use, mode of infant delivery (vaginal or caesarean section), infant sex, Apgar score, birth weight, birth length, and birth $\mathrm{HC}$. We also collected neonatal complications, including death, hospitalisation in a neonatal unit, respiratory distress that 
required treatment (intubation or noninvasive ventilation), and intraventricular haemorrhage > grade 1 in Papile's classification (22).

\section{Primary measurement outcome}

To evaluate infant growth at 9 months postnatal age, we recorded weight, height, and HC. Catch-up growth was defined as increases in weight, height, and HC that achieved $\geq$ -2 SD of reference values listed in World Health Organisation growth curve charts (23).

\section{Secondary measurement outcome}

For the neurodevelopmental screening at 9 months postnatal age, we studied five items derived from the Brunet-Lezine test (24). These items were systematically and prospectively recorded by paediatricians during the standardised 9-month routine visit required in our national follow-up programme. Each practitioner checks these items, according to the very precise criteria described in the Brunet-Lezine test, after an actual office examination. To cover different areas of neurodevelopment (posture, coordination, language, sociability), we chose 5 standardized items: sitting without support, moving (crawling and/or walking on all fours), pointing (child finger pointing at an object/person), thumb-index grip (seizure of a pellet between thumb and index), and the child's reaction to his/her own name. Neurodevelopmental screening was considered normal when a child achieved these five items.

\section{Statistical analysis}

A trusted third party reconciled the available data from two separate sources (Medical records from the Regional Maternity Hospital and the 9-month certificates from the Departmental database) at each step, based on the identity of the mothers and infants. The file was then anonymised with a study number for each mother-child pair and submitted for blinded analysis.

Variables are expressed as the mean \pm SD or the median and interquartile variations. Categorical variables were compared with the Chi-2 test or exact Fisher test. Continuous 
variables were compared with the Mann-Whitney test or Student $t$ test. A significance level of $p<.05$ was used in all analyses. Data were analysed by statisticians of the medical information department of our institution with SAS statistical v.9.2 (SAS institute, Cary, NC, USA).

\section{Ethics}

Parents were systematically informed of the possible use of medical information about their children at the time of birth. All parents provided written informed consent. This study received approval from the Ethics Committee of the Regional Maternity Hospital of Nancy (Number: MRU.11.06) and the French Commission of Data Protection (CNIL Number: DR-2011-388).

\section{Results}

\section{General characteristics of the study population}

During the studied period, 6586 infants were born in our institution. We selected 202 infants according to the inclusion criteria. Eight infants were excluded secondarily due to genetic disease or missing data. Finally, 194 infants were eligible, born at term with birth weight below the $5^{\text {th }}$ percentile of the standard growth curves. Of those, 75 infants $(39 \%)$ were SYM SGA and $119(61 \%)$ were aSYM SGA. Data at 9 months of age could be collected for 136 (70\%) infants. Infant characteristics are presented in Table 1.

The antenatal diagnosis of FGR was only suspected in $47.9 \%$ of pregnancies that delivered a child that was eventually diagnosed SGA. The FGR was diagnosed between 18 and 38 weeks gestational age, with peaks at 22 and 32 weeks, which are the key periods for routine ultrasound pregnancy monitoring in France. The SYM and aSYM groups were not different in gestational age at FGR diagnosis. In the neonatal period, the aetiological diagnosis was only recorded in $29 \%$ of the paediatric files. However, based on our study criteria, we were retrospectively able to establish an aetiological diagnosis of FGR in $82.5 \%$ of the SGA infants with data found in both neonates and maternal 
medical records. Etiologic diagnoses are shown in Table 2. No significant differences were observed between groups in the aetiologies of FGR but smoking. There was no case of materno-foetal infection.

At 9 months of age, 136 certificates were found and analysed. We compared the group of followed infants and the group infants lost to follow-up (Table 3). Infants lost to followup were from families with a lower socioeconomic status than those of the followed infants.

The 9-month physical examination was performed at a similar age in the SYM and aSYM SGA groups (9.15 \pm 0.66 vs. $9.12 \pm 0.6$ months; $p=0.75)$.

\section{Primary outcome}

Catch-up growth (for all three parameters: weight, height, and HC) was 79\% (107/136) at 9 months of age for overall SGA infants. Twenty one percent of the infants $(29 / 136)$ didn't catch-up growth for one or more parameters, including four infants with no catchup for all three parameters.

More infants in the aSYM SGA group showed catch-up growth than in the SYM group (85\% vs. 70\%, $p=.03$; Table 4). Also, the SYM group showed significantly lower HC than that of the aSYM group $(43.7 \pm 1.2 \mathrm{~cm}$ vs. $44.9 \pm 1.6 \mathrm{~cm}, \mathrm{p}<.0001)$. The aetiological diagnosis of FGR for SGA infants without catch-up growth was mainly placental origin or maternal smocking.

\section{Secondary outcome}

At 9 months of age, $83(61 \%)$ infants had normal neurodevelopmental screening whereas $53(39 \%)$ showed a delay in one or more areas (Table 5). There was no statistically significant difference between SYM and aSYM SGA groups.

Among infants with a delay in one or more areas, the distribution of aetiologies for the FGR diagnosis was as follows: placental origin (32\%), maternal smoking (20.7\%), 
other/undetermined (20.7\%), chronic maternal disease (19\%), and maternal addiction (7.6\%).

Thirty seven percent (40/107) of the infants with an overall catch-up growth have at least one delayed item in the neurodevelopmental screening at 9 months of age, versus $41 \%$ $(12 / 29)$ of the infants who didn't catch-up growth for one or more parameters $(p=0.7)$.

All infants without any catch-up growth parameter $(n=4)$ had at least one delayed item, versus $37.5 \%$ of the infants with global catch-up growth $(p=0.01)$.

\section{Discussion}

Our study showed that catch-up growth at 9 months was significantly different in SYM and aSYM SGA term infants: aSYM SGA infants showed better catch-up growth than SYM SGA infants. Ten percent of SYM SGA infants had a smaller HC than the reference values at 9 months of age. The overall catch-up growth rate observed in our population at 9 months is similar to the results of Saenger et al. (11) and Harding et al. (12). Both studies found catch-up growth rates of 75 to $80 \%$ at 6 months of age. With regards to SGA characteristic, SYM or aSYM, Jelliffe-Pawlowski et al. (3) found that SYM SGA infants remained significantly smallness at one year of age as compared to infants born aSYM SGA which is consistent with our study. Also, as in our study, Ochiai et al. (17) and Kaur et al. (25) found that more SYM SGA infants had persistent smaller $\mathrm{HC}$ at one year of age than aSYM SGA infants. In the study by Jelliffe-Pawlowski et al. (3) the difference observed on HC at one year of age between SYM and aSYM SGA was not improved at four years of age. In our study, two infants with $\mathrm{HC} \leq-2 \mathrm{SD}$ of the reference value at 9 months of age had initial $\mathrm{HC}$ in the upper $5^{\text {th }}$ percentile of the AUDIPOG growth curves; both infants had aSYM FGR of placental origin. This result was surprising, and it is possible that another disease might have caused this poor brain 
growth; however, the small number of infants suggested that this may be a marginal observation.

Overall, $39 \%$ of SGA infants had at least one missing item in their neurodevelopmental screening in our study. However, in the Department of Meurthe-etMoselle, 6030 infants were assessed by the Brunet-Lezine test items at 9 months of age, according to the national healthcare follow-up programme: $60.5 \%$ of them had normal neurodevelopmental screening, and $39.5 \%$ had at least one item failure (26). This is not different from our SGA population, but this age of evaluation is probably too early to allow definitive reliable prognosis. The Brunet-Lezine test evaluates postural and motor development, relationships with objects, and socialisation of infants (24). At 9 months, results are difficult to interpret, because this age seems indeed too early for definitive neurological concern. Abnormalities at 9 months should probably be considered as a warning, rather than a definitive problem, and calls for close monitoring of neurological development. Several paediatric studies showed worse neurological development in infants born SGA than their AGA controls $(3,14,15)$. In addition, two recent reviews showed that SGA infants born at term were associated with long-term deficiencies in neurodevelopment $(27,28)$.

The lack of difference between SYM and aSYM SGA groups for neurodevelopmental screening at 9 months postnatal age is similar to those from JelliffePawlowski et al (3). In that study, infants born at term were evaluated for neurological function at 8 months of age, and they also found no differences between SYM SGA infants and aSYM SGA infants. However, other authors highlight differences for neurodevelopment between SYM and aSYM SGA infants. The study by Goto et al. (29) showed that neurodevelopment at 2 months of age was worse in SYM SGA infants born at term compared to aSYM SGA infants, but this evaluation was indeed too early for reliable diagnosis. On the other hand, Leitner et al. (16) showed that the neurodevelopment index at 9 years old was lower in an SGA group than in an AGA 
group, particularly in infants with SYM SGA. They also found that, among the SGA infants, somatic catch-up growth at age 2 correlated with neurodevelopmental outcome at 9 years of age (16).

In our study, all infants without any catch-up growth parameter had at least one abnormal item in the standardised neurological development assessment. Although the numbers were small, this result is consistent with the idea that postnatal catch-up growth is linked to neurological development. Ochiai et al. (17) and Frisk et al. (18) highlighted that neurodevelopment reached a higher level at 6-7 years of age for infants born SGA who had caught up to a normal $\mathrm{HC}$ at 9-12 months of age as compared to those who didn't catch up at 9-12 months. Similarly, Klaric et al. (19) observed that delayed brain growth was associated with impaired neurological development at 6 years of age in a population of term infants with FGR. In a study by Fattal-Valevski et al. (20), 136 children born SGA were followed from birth to 9-10 years of age with annual growth measurements and neurodevelopment evaluations. They found that the cognitive outcome at 9-10 years correlated well with the $\mathrm{HC}$ at all ages; moreover, the neurodevelopment outcome at 9-10 years also correlated with the weight at all ages.

These data prompt us to emphasise the importance of closely monitoring growth, especially brain growth, in all infants born SGA. Indeed, term SGA newborns have few perinatal and neonatal complications, but they may have long-term growth and neurodevelopment complications. This is a very important point, because our study illustrates that SGA seems not to be a concern when infants were born at term. Half of FGR suspicion only was reported in prenatal evaluation when the information was available in the mothers' file. In addition, only half of these suspected cases were appropriately investigated. This low diagnosis rate may also be explained in part by the low reliability of biometrics for a foetus close to term and in part by some late appearance of FGR, in the $3^{\text {rd }}$ trimester of the pregnancy. Nevertheless, obstetrical interest was modest for diagnosing FGR in these foetuses close to term, probably because the 
expected rate of acute perinatal complications was low. However, we were able to determine a probable diagnosis in more than $80 \%$ of the files. The only difference observed between the two groups was a higher rate of maternal smoking in the ASYM SGA group than in the SYM SGA group. In particular, the rate of placental origin was similar in the aSYM and SYM groups. These results were similar to those observed by al Riyami et al (6). Infants without global catch-up growth and/or worse neurodevelopmental screening at 9 months of age mainly had FGR of a placental origin, or due to maternal smoking. The small numbers in each group prevented adequate statistical analysis. However, this observation was interesting, because it did not support the classic notion that FGR of placental origin has a better outcome than FGR of other origins.

There was no difference between the two groups for gestational age at FGR diagnosis; this finding opposed the classic notion that SYM FGR appears earlier during pregnancy and aSYM FGR appears later $(5,6)$.

Our study has some limitations. It was a retrospective study with small numbers. In some subgroups, preventing statistical analysis, and confirmation is required. Distribution of infants in the different groups of aetiology may lack precision. For instance, few placentas were actually analysed. Thus, the definition of the placenta aetiology group mainly relies upon clinical and Doppler data. Likewise, classification in the maternal addiction group was decided after maternal interview. Thus, some mothers may have not properly declared their addiction. However, the most severe situation requiring drug substitution was recorded. Overall, because of the retrospective design of our study, clinical associations may have been found in patients' files but etiologic relationship cannot be firmly established. The growth curves used in this study came from different sources at birth and at 9 months, because data were not available for a single longitudinal curve appropriate for our population. We chose the $5^{\text {th }}$ percentile of the AUDIPOG growth curves to avoid including constitutionally small children. The rate of 
children lost at 9 months of age was rather high, particularly in the most disadvantaged populations, which could have introduced a bias. The neurological evaluation was performed early, which prevented drawing firm conclusions, but 9 months is the standardised age of the national follow-up network programme, and it provided a good estimation. We have to remain careful on the interpretation of the results because this evaluation is based on few screening items only and not on a complete developmental assessment. Another limitation was the lack of a control group; however, the standardised neurological test has been used since 1970 and data are available for the general population.

In conclusion, term SYM SGA infants showed less catch-up growth at 9 months of age than term aSYM SGA infants, and this was even more noticeable for HC. Neurodevelopment was similar between the groups, and similar to the general population at 9 months of age, but the assessment was too early to draw final conclusion. In addition infants without any catch-up growth parameter at 9 months seem at higher risk of poor neurological outcome. Thus, SGA outcome of term infants appears to be underestimated, when it looks important to recognize them, monitor their growth and neurodevelopment, to diagnose those without appropriate catch-up growth.

\section{Acknowledgements}

We thank Dr COLOMBO MC from the Maternal and Child Protection Department of Meurthe-et-Moselle for assistance in the recovery of 9-month follow-up files.

\section{Conflict of interest statement:}

The authors declare no conflicts of interests 


\section{References}

1. Lubchenco LO, Hansman C, Dressler M, Boyd E. Intrauterine growth as estimated from liveborn birth weight data at 24 to 42 weeks gestation. Pediatrics 1963; 32: 793-800.

2. Lee PA, Chernausek SD, Hokken-Koelega ACS, Czernichow P. International Small for Gestational Age Advisory Board consensus development conference statement: management of short children born small for gestational age, April 24-October 1, 2001. Pediatrics 2003; 111: 1253-61.

3. Jelliffe-Pawlowski LL, Hansen RL. Neurodevelopmental outcome at 8 months and 4 years among infants born full-term small-for-gestational-age. J Perinatol 2004; 24: 505-14.

4. Rodríguez G, Collado MP, Samper MP, Biosca M, Bueno O, Valle S, et al. Subcutaneous fat distribution in small for gestational age newborns. $J$ Perinat Med 2011; 39: 355-7

5. Vik T, Vatten L, Jacobsen G, Bakketeig LS. Prenatal growth in SYM and aSYM small-for-gestational-age infants. Early Hum Dev 1997; 48: 167-76.

6. Al Riyami N, Walker MG, Proctor LK, Yinon Y, Windrim RC, Kingdom JCP. Utility of head/abdomen circumference ratio in the evaluation of severe early-onset intrauterine growth restriction. J Obstet Gynaecol Can 2011; 33: 715-19.

7. Pallotto EK, Kilbride HW. Perinatal outcome and later implications of intrauterine growth restriction. Clin Obstet Gynecol 2006; 49: 257-69.

8. Mclntire DD, Bloom SL, Casey BM, Leveno KJ. Birth weight in relation to morbidity and mortality among newborn infants. N Engl J Med 1999; 340: 1234-8.

9. Qiu X, Lodha A, Shah PS, Sankaran K, Seshia MMK, Yee W, et al. Neonatal Outcomes of Small for Gestational Age Preterm Infants in Canada. Am J Perinato/2012; 29: 87-94. 
10. Doctor BA, O'Riordan MA, Kirchner HL, Shah D, Hack M. Perinatal correlates and neonatal outcomes of small for gestational age infants born at term gestation. Am J Obstet Gynecol 2001; 185: 652-9.

11. Saenger P, Czernichow P, Hughes I, Reiter EO. Small for gestational age: short stature and beyond. Endocr Rev 2007; 28: 219-51.

12. Harding JE, McCowan LME. Perinatal predictors of growth patterns to 18 months in children born small for gestational age. Early Hum Dev 2003; 74: 13-26.

13. Claris O, Beltrand J, Levy-Marchal C. Consequences of intrauterine growth and early neonatal catch-up growth. Semin Perinatol 2010; 34: 207-10.

14. Geva R, Eshel R, Leitner Y, Valevski AF, Harel S. Neuropsychological outcome of children with intrauterine growth restriction: a 9-year prospective study. Pediatrics 2006; 118: $91-100$.

15. Lundgren M, Cnattingius S, Jonsson B, Tuvemo T. Intellectual performance in young adult males born small for gestational age. Growth Horm IGF Res 2004; 14 Suppl: S7-8.

16. Leitner Y, Fattal-Valevski A, Geva R, Eshel R, Toledano-Alhadef H, Rotstein M, et al. Neurodevelopmental outcome of children with intrauterine growth retardation: a longitudinal, 10-year prospective study. J Child Neurol 2007; 22: 580-7.

17. Ochiai M, Nakayama H, Sato K, lida K, Hikino S, Ohga S, et al. Head circumference and long-term outcome in small-for-gestational age infants. J Perinat Med 2008; 36: 341-7.

18. Frisk $\mathrm{V}$, Amsel $\mathrm{R}$, Whyte $\mathrm{H}$. The importance of head growth patterns in predicting the cognitive abilities and literacy skills of small-for-gestational-age children. Dev Neuropsychol 2002; 22: 565-93. 
19. Klaric A, Galic S, Kolundzic Z, Bosnjac V. Neuropsychological development in preschool children born with aSYMal intrauterine growth restriction and impact of postnatal head growth. J Child Neurol 2013; 28: 867-873.

20. Fattal-Valesvski A, Toledano-Alhadef H, Leitner Y, Geva R, Eshel R, Harel S. Growth patterns in children with intrauterine growth retardation and their correlation to neurocognitive development. J Child Neurol 2009; 24: 846-51.

21. Mamelle N, Munoz F, Grandjean H. [Fetal growth from the AUDIPOG study. I. Establishment of reference curves. J Gynecol Obstet Biol Reprod (Paris) 1996; 25: 61-70.

22. Papile LA, Burstein J, Burstein R, Koffler H. Incidence and evolution of subependymal and intraventricular hemorrhage: a study of infants with birth weights less than 1,500 gm. J Pediatr 1978; 92: 529-34.

23. De Onis M, Garza C, Victora CG, Onyango AW, Frongillo EA, Martines J. The WHO Multicentre Growth Reference Study: planning, study design, and methodology. Food Nutr Bull 2004; 25(Suppl): S15-26.

24. Josse D. Brunet-Lézine Révisé : Echelle de développement psychomoteur de la première enfance. Manuel BLR-C. Ed. Applications psychologiques; Paris; 1997:pp307. 25. Kaur H, Bhalla AK, Kumar P. Longitudinal growth of head circumference in term SYM and aSYM small for gestational age infants. Early Hum Dev 2012; 88: 473-8.

26. Protection Maternelle et Infantile. La santé de la mère et de l'enfant, chiffres clés en 2012 en Meurthe et Moselle. Conseil Général de Meurthe et Moselle. http://www.cg54.fr/uploads/media/Chiffres cles PMI 2012-BD Bonne version.pdf. 27. Gascoin G, Flamant C. Long-term outcome in context of intra uterine growth restriction and/or small for gestationel age newborns. J Gynecol Obstet Biol Reprod 2013; 42: 911-20. 
28. Arcangeli T, Thilaganathan B, Hooper R, Khan K.S, Bhide A. Neurodevelopment delay in small babies at term : a systematic review. Ultrasound Obstet Gynecol 2012; 40: 267-75.

29. Goto MMF, Gonçalves VMG, Netto AA, Morcillo AM, Moura-Ribeiro MVL de. Neurodevelopment of full-term small-for-gestational age infants in the second month of life. Arq Neuropsiquiatr 2005; 63: 75-82.

A. Lubchenco LO, Hansman C, Boyd E. Intrauterine growth in length and head circumference as estimated from live births at gestational ages from 26 to 42 weeks. Pediatrics 1966;37:403-8. 
Table 1: Demographic characteristics of the study population

\begin{tabular}{|c|c|c|c|c|}
\hline & $\begin{array}{l}\text { Study } \\
\text { Population }\end{array}$ & SYM SGA & aSYM SGA & P-value \\
\hline $\mathrm{N}$ & 194 & 75 & 119 & \\
\hline Maternal age (years) & $28.8 \pm 5.5$ & $29.1 \pm 5.3$ & $28.5 \pm 5.7$ & .46 \\
\hline Social worker support & $17(8.8 \%)$ & $6(8 \%)$ & $11(9.2 \%)$ & .82 \\
\hline Social health insurance & $25(12.8 \%)$ & $10(13.3 \%)$ & $15(12.6 \%)$ & .11 \\
\hline Primigravida & $89(45.8 \%)$ & $34(45.3 \%)$ & $55(46.2 \%)$ & .35 \\
\hline Caesarean section & $50(25.7 \%)$ & $17(22.6 \%)$ & $33(27.7 \%)$ & .43 \\
\hline Male & $102(52.5 \%)$ & $47(62.6 \%)$ & $55(46.2 \%)$ & $.025^{*}$ \\
\hline Gestational age (weeks) & $39.3 \pm 1.2$ & $39.1 \pm 1$ & $39.4 \pm 1.2$ & .11 \\
\hline Birth weight (g) & $2438 \pm 233$ & $2423 \pm 224$ & $2447 \pm 239$ & .49 \\
\hline Birth length (cm) & $45.6 \pm 1.7$ & $45.4 \pm 1.7$ & $45.8 \pm 1.7$ & .07 \\
\hline Birth HC $(\mathrm{cm})$ & $32.3 \pm 1.3$ & $31.3 \pm 0.9$ & $33 \pm 1$ & $.0001^{*}$ \\
\hline Apgar $\leq 6$ at $1 \mathrm{~min}$ & $26(13.4 \%)$ & $9(12 \%)$ & $17(14.3 \%)$ & .40 \\
\hline Apgar $\leq 6$ at $5 \mathrm{~min}$ & $6(3.1 \%)$ & $2(2.6 \%)$ & $4(3.3 \%)$ & .78 \\
\hline Death & 0 & 0 & 0 & \\
\hline RD & $16(8.2 \%)$ & $9(12 \%)$ & $7(5.9 \%)$ & .13 \\
\hline IVH & $1(0.5 \%)$ & 0 & $1(0.8 \%)$ & .30 \\
\hline Hospitalisation & $54(27.8 \%)$ & $20(26.7 \%)$ & $34(28.5 \%)$ & .77 \\
\hline
\end{tabular}

Values represent the mean $\pm \mathrm{SD}$ or $\mathrm{N}(\%)$, as indicated. $* \mathrm{p}<.05$

SYM: symmetric; aSYM: asymmetric; SGA: small for gestational age; HC: Head circumference, RD: Respiratory Distress, IVH: Intraventricular haemorrhage. 
Table 2: Aetiologic diagnosis of foetal growth restriction

\begin{tabular}{|c|c|c|c|c|}
\hline & $\begin{array}{l}\text { Study } \\
\text { Population }\end{array}$ & SYM SGA & aSYM SGA & $\mathrm{P}$-value \\
\hline $\mathrm{N}$ & 194 & 75 & 119 & \\
\hline Placental origin & $69(35.6 \%)$ & $30(40 \%)$ & $39(32.7 \%)$ & .31 \\
\hline $\begin{array}{l}\text { Isolated maternal } \\
\text { hypertension }\end{array}$ & $46(23.7 \%)$ & $19(25.3 \%)$ & $27(22.7 \%)$ & .67 \\
\hline $\begin{array}{l}\text { Preeclampsia, HELLP } \\
\text { syndrom, eclampsia }\end{array}$ & $13(6.7 \%)$ & $4(5.3 \%)$ & $9(7.5 \%)$ & .54 \\
\hline Doppler abnormalities & $25(13 \%)$ & $12(16 \%)$ & $13(10.9 \%)$ & 0.19 \\
\hline $\begin{array}{l}\text { Histopathological lesions } \\
\text { of placenta }\end{array}$ & $31(16 \%)$ & $11(14.7 \%)$ & $20(16.8 \%)$ & 0.13 \\
\hline $\begin{array}{l}\text { Isolated Maternal } \\
\text { smoking }\end{array}$ & $49(25.2 \%)$ & $13(17.3 \%)$ & $36(30.2 \%)$ & $.043 *$ \\
\hline Maternal addiction & $24(12.4 \%)$ & $10(13.3 \%)$ & $14(11.7 \%)$ & .75 \\
\hline $\begin{array}{l}\text { Chronic maternal } \\
\text { disease }\end{array}$ & $18(9.3 \%)$ & $9(12 \%)$ & $9(7.6 \%)$ & .29 \\
\hline Diabetes & $6(3.1 \%)$ & $3(4 \%)$ & $3(2.5 \%)$ & NS \\
\hline Endocrine disorders & $3(1.5 \%)$ & $1(1.3 \%)$ & $2(1.7 \%)$ & NS \\
\hline Autoimmune disease & $3(1.5 \%)$ & $1(1.3 \%)$ & $2(1.7 \%)$ & NS \\
\hline $\begin{array}{l}\text { Other maternal chronic } \\
\text { disease }\end{array}$ & $6(3.1 \%)$ & $4(5.3 \%)$ & $2(1.7 \%)$ & NS \\
\hline Undetermined/other & $34(17.5 \%)$ & $13(17.3 \%)$ & $21(17.6 \%)$ & .95 \\
\hline
\end{tabular}

Values represent the number of individuals, $\mathrm{N}(\%)$, as indicated. ${ }^{*} \mathrm{p}<.05$

SYM: symmetric; aSYM: asymmetric; SGA: small for gestational age; NS : Not

Significant 
Table 3: Demographic, socio-economic, perinatal, and neonatal characteristics of infants followed or lost to follow-up at 9 months of age

\begin{tabular}{|c|c|c|c|}
\hline & Followed & Lost to follow-up & P-value \\
\hline $\mathrm{N}$ & 136 & 58 & \\
\hline Maternal age (yrs) & $29.1 \pm 5.6$ & $27.4 \pm 5.6$ & $.02 *$ \\
\hline Support by Social worker & $8(5.9 \%)$ & $9(15.5 \%)$ & $.02 *$ \\
\hline Social Health Insurance & $14(10.3 \%)$ & $11(18.9 \%)$ & $.048 *$ \\
\hline Primigravida & $64(47 \%)$ & $25(43.1 \%)$ & .52 \\
\hline Caesarean section & $36(26.5 \%)$ & $14(24.1 \%)$ & .73 \\
\hline Male & $76(55.9 \%)$ & $26(44.9 \%)$ & .16 \\
\hline Gestational age (weeks) & $39.4 \pm 1.1$ & $39.1 \pm 1.2$ & .09 \\
\hline Birth weight (g) & $2458 \pm 228$ & $2390 \pm 239$ & .06 \\
\hline Birth length (cm) & $45.8 \pm 1.8$ & $45.3 \pm 1.7$ & .07 \\
\hline Birth HC $(\mathrm{cm})$ & $32.3 \pm 1.3$ & $32.2 \pm 1.2$ & .55 \\
\hline SYM SGA & $41.2 \%$ & $32.7 \%$ & .27 \\
\hline Apgar $<7$ at $1 \mathrm{~min}$ & $21(15.4 \%)$ & $5(8.6 \%)$ & .43 \\
\hline Apgar $<7$ at $5 \mathrm{~min}$ & $5(3.7 \%)$ & $1(1.7 \%)$ & .47 \\
\hline Death & 0 & 0 & \\
\hline $\mathrm{RD}$ & $14(10.3 \%)$ & $2(3.4 \%)$ & .11 \\
\hline IVH & $1(0.7 \%)$ & 0 & .58 \\
\hline Hospitalisation & $38(27.9 \%)$ & $16(27.6 \%)$ & .95 \\
\hline \multicolumn{4}{|l|}{ Aetiologic diagnosis of FGR } \\
\hline Placental origin & $46(33.8 \%)$ & $23(39.6 \%)$ & .43 \\
\hline Maternal smoking & $33(24.2 \%)$ & $16(27.6 \%)$ & .62 \\
\hline Maternal addiction & $13(9.5 \%)$ & $11(18.9 \%)$ & .06 \\
\hline Chronic maternal disease & $16(11.7 \%)$ & $2(3.4 \%)$ & .06 \\
\hline Other/undetermined & $27(19.8 \%)$ & $7(12 \%)$ & .19 \\
\hline
\end{tabular}

Values represent the mean \pm SD or $\mathrm{N}(\%)$. ${ }^{*} \mathrm{p}<.05$; SYM SGA: symmetric small for gestational age, HD: Head circumference, RD: Respiratory Distress, IVH: Intraventricular haemorrhage. 
Table 4: Weight, height, and head circumference at 9 months of age of SYM and aSYM SGA infants

\begin{tabular}{|l|l|l|l|l|}
\hline & $\begin{array}{l}\text { Study Population } \\
(\mathrm{n}=136)\end{array}$ & $\begin{array}{l}\text { SYM SGA } \\
(\mathrm{n}=56)\end{array}$ & $\begin{array}{l}\text { aSYM SGA } \\
(\mathrm{n}=80)\end{array}$ & $\begin{array}{l}\text { P- } \\
\text { value }\end{array}$ \\
\hline Weight $(\mathrm{kg})$ & $8 \pm 0.9$ & $7.9 \pm 0.9$ & $8.1 \pm 0.9$ & .25 \\
\hline $\begin{array}{l}\text { Weight z-score } \leq-2 \mathrm{SD} \\
(\mathrm{n}-\%)\end{array}$ & $17(12.5 \%)$ & $11(19.7 \%)$ & $6(7.5 \%)$ & $.035^{*}$ \\
\hline Height $(\mathrm{cm})$ & $69.4 \pm 2.9$ & $69.2 \pm 3.2$ & $69.5 \pm 2.6$ & .56 \\
\hline $\begin{array}{l}\text { Height } \mathrm{z}-\mathrm{score} \leq-2 \mathrm{SD} \\
(\mathrm{n}-\%)\end{array}$ & $19(13.9 \%)$ & $11(19.7 \%)$ & $8(10.1 \%)$ & .11 \\
\hline HC $(\mathrm{cm})$ & $44.4 \pm 1.6$ & $43.7 \pm 1.2$ & $44.9 \pm 1.6$ & $.0001^{*}$ \\
\hline $\begin{array}{l}\text { HC z-score } \leq-2 \text { SD } \\
(\mathrm{n}-\%)\end{array}$ & $8(5.9 \%)$ & $6(10.7 \%)$ & $2(2.5 \%)$ & $.03 *$ \\
\hline
\end{tabular}

Values represent the mean $\pm \mathrm{SD}$ or $\mathrm{N}(\%)$, as indicated. $* \mathrm{p}<.05$

SYM: symmetric; aSYM: asymmetric; SGA: small for gestational age; SD: standard deviations; HC: Head circumference. 
Table 5. Psychomotor development (Brunet-Lezine test) at 9 months of age of SYM and aSYM SGA infants

\begin{tabular}{|l|l|l|l|l|}
\hline & Study Population & SYM SGA & aSYM SGA & P-value \\
\hline N $(\%)$ & 136 & 56 & 80 & \\
\hline No sitting & $4(2.9 \%)$ & $1(1.8 \%)$ & $3(3.8 \%)$ & .38 \\
\hline No moving & $15(11 \%)$ & $6(10.7 \%)$ & $9(11.2 \%)$ & .80 \\
\hline No pointing & $38(28.7 \%)$ & $16(28.6 \%)$ & $22(27.5 \%)$ & .98 \\
\hline No thumb-index grip & $4(2.9 \%)$ & 0 & $4(5 \%)$ & .23 \\
\hline $\begin{array}{l}\text { No reaction to own } \\
\text { name }\end{array}$ & $5(3.7 \%)$ & $4(7.1 \%)$ & $1(1.2 \%)$ & .07 \\
\hline
\end{tabular}

SYM: symmetric; aSYM: asymmetric; SGA: small for gestational age. 